\title{
Formation of the "Multinational Health Service" is to blame for financial crisis in the NHS
}

This Letter (BMJ 2013;347:f4864, doi:10.1136/bmj.f4864) incorrectly states that "Serco is being investigated by the Serious Fraud Office for allegedly cheating the government over tagging schemes for offenders." We apologise for this mistake.
Cite this as: BMJ 2013;347:f5130

๑ BMJ Publishing Group Ltd 2013 